\title{
Relationship Between the Demographic Variables and Prevalence of Depression Among the University Stu- dents
}

\author{
*Abou Bakar Idrees Awan \\ Institute of Mental \& Behavioral Sciences, Pakistan \\ *Corresponding author: Abou Bakar Idrees Awan, Institute of Mental \& Behavioral Sciences, Rawalpindi, Punjab, Pakistan
}

\begin{tabular}{|c|c|}
\hline ARTICLE INFO & ABSTRACT \\
\hline Received: April 23, 2019 & The study explores the prevalence of depression among students of Different Nation- \\
\hline Published: April 30, 2019 & $\begin{array}{l}\text { alities at International Islamic University, Islamabad, and its relationship with the demo- } \\
\text { graphic variables. The DASS } 21 \text { was administered to } 80(N=80 \text {, Female } n=40 \text {, male } n=40)\end{array}$ \\
\hline $\begin{array}{l}\text { Citation: *Abou Bakar Idrees Awan. Re- } \\
\text { lationship Between the Demographic }\end{array}$ & $\begin{array}{l}\text { their mean age was } 20.22 \text {, students from the different faculties of the University. Data Anal- } \\
\text { ysis shows that there is a significant positive relationship between the prevalence depres- } \\
\text { sion and the demographic variables i.e., boarding, parents' income, gender and culture. }\end{array}$ \\
\hline
\end{tabular}

Variables and Prevalence of Depression

Among the University Students. Biomed

J Sci \& Tech Res 17(4)-2019. BJSTR.

MS.ID.003031.

\section{Introduction}

Depression is a complex disorder [1]. Depression is affecting badly student's motivation, concentration, feelings of self-worth, mood and these days it is becoming a very common problem in students of any age, gender, socio economic status, ethnicity and year level nationality (Andrews \& Wilding 2004). i.e., without the cultural boundaries. Depressions have severe impacts on the student's academic performance and social functioning within the university environment. [2-5] Competitions for higher merits in jobs, exams, inability to cope, helplessness, increased psychological pressure, mental tension and too much work load made the educational process a stressful process. While studying at the university there are many situations and interpersonal instances that gave rise to the feeling of hopelessness, sorrow, or being alone, i.e., the onset of depression, such as the family environment, the socialization setting, and the discrimination against gender.

Researchers like [6-8] have stressed that educational processes can lead to prevailing the depression in the jobs and later life. Interpersonal relationships can be one of the causes of the Depression; relationships within the family e.g., the impact of depressed parents can have an effect on their children as well, the social environment, interactions between genders. This poor interpersonal relationship leads to the feeling of lack of control and having a high risk of conflict, rejection, and low self-esteem which ultimately leads to the depression. Similarly, the family and social class, income and living in hostel have impact on a depressed individual (Hammen \& Brennan 2001) [9,10]. Students facing and managing financial problems have increased risk of depression (Andrews \& Wilding 2004). Gender discrimination in the society has also a relationship with the prevailing of the depression. Female students must face increased expectations to conform to the standards set forth by society and culture.

\section{Rationale of the Study}

As the Depression in students is a common problem, the role of demographic variables in prevalence of the depression is still unclear. The present study investigated the differences in depression level of students based on demographic variables.

\section{Methodology}

\section{Objectives}

The will examine the effect of age, economic status, and living arrangement (accommodation) on the depression level of students. 


\section{Operational Definitions of Variables}

Demographic Variables: The demographic variables for the present study will be gender (male students and female students), Socioeconomic status will be measured by the monthly income of the parents in two categories i.e., how are getting s.15000/= P.M will be labelled as Low Income Group and having more than Rs.15000/= will be labelled as High income group, and those who are studying in the university and living at home will be labelled as Day Scholars and those who are residing at the Hostels will be labelled as Borders.

Depression: Depression for the present study will be measured through Depression Anxiety Stress Scale (DASS), Lovibond \& Lovibond (1995). High scores on the scale will display high depression among students and low scores will display low depression.

\section{Hypotheses:}

a) Higher levels of depression would be found for females as compared to the males.

b) Students of the low-income parents would be having more levels of depression as compared to the higher level of the depression. c) High levels of depression would be found for students living in the hostels as compared to the Boarders

\section{Procedure}

The students of the three leading universities of Rawalpindi \& Islamabad were taken as the sample of the study, a sample of the $N=80$ (both male $n=40$ and female $n=40$ ) out which $n=20$ in the both samples were living in the hostels and $n=20$ in the both samples were boarder students. Students during the study hours were give the DASS based on the convenient sampling. DASS (Depression Anxiety Scale) and a bio data sheet for recording Demographic variables (Age, Gender, Boarder or day scholar and Family income) were used as the instruments in the study. The DASS 21 is a set of three self-report scales i.e., Depression Scale, Anxiety Scale, Stress Scale designed to measure the negative emotional states of depression, anxiety and stress. T Test was performed for Statistical Analysis for determining the association between socio demographic variables and scores on DASS.

\section{Results \& Discussion}

The following table shows the relationship between the demographic variable and the scores on the DASS i.e., the levels of the depression on the DASS (Tables 1-3).

Table 1: Show Mean, Standard Deviation and $t$ values for male and female students the results show significant mean differences on the scores of DASS with respect to Gender. Females have higher scores $(\mathrm{M}=20.22, \mathrm{t}=7.80, d f=78, P<.01)$ as compared to male students $(M=27.97, \mathrm{t}=5.10, d f=78, P<.01)$.

\begin{tabular}{|c|c|c|c|c|}
\hline \multicolumn{5}{|c|}{ Differences on the scores on DASS and Gender (N=80) } \\
\hline Group & $\mathbf{n}$ & $\mathbf{M}$ & SD & \\
\hline Boys & 40 & 20.22 & 6.88 & t \\
\hline Girls & 40 & 27.97 & 3.67 & 5.10 \\
\hline
\end{tabular}

$D f=78, P<.01$

Table 2: Show Mean, Standard Deviation and t values among students of the different financial backgrounds. The results show significant mean differences on the scores of DASS with respect to Gender. Students of low-income parents have higher scores (M=32.33, $\mathrm{t}=4.48, \mathrm{df}=78, P<.01)$ as compared to students of high-income parents $(M=33.33, \mathrm{t}=7.80, d f=78, P<.01)$.

\begin{tabular}{|c|c|c|c|c|}
\hline \multicolumn{5}{|c|}{ Differences on the scores of DASS and Financial back ground (N=80) } \\
\hline Group & $\mathbf{n}$ & $\mathbf{M}$ & SD & 7.56 \\
\hline High Income Parents & 48 & 24.66 & 4.77 & t \\
\hline Low income Parents & 32 & 32.33 & 4.48 \\
\hline
\end{tabular}

$D f=78, P<.01$

Table 3: Show Mean, Standard Deviation and t values among Day Scholar and Boarder students. The results show significant mean differences on the scores of DASS with respect to living in hostel and home. Boarders have higher scores $(\mathrm{M}=28.88, \mathrm{t}=5.20, d f=78$, $P<.01)$ as Day Scholars compared to students of high-income parents $(M=34.11, \mathrm{t}=5.20, d f=298, P<.01)$.

\begin{tabular}{|c|c|c|c|c|}
\hline \multicolumn{3}{|c|}{ Differences on the scores of DASS and Financial back ground (N=80) } \\
\hline Group & n & M & SD \\
\hline Day Scholars & 40 & 28.88 & 4.55 \\
\hline Boarders & 40 & 34.11 & 6.12 \\
\hline
\end{tabular}

$D f=78, P<.01$ 


\section{Discussion}

The results of the first analyses indicated that depression levels were affected by different demographic characteristics Hypotheses demographic variables significantly associated with depression levels included gender, employment status and boarding. Female students experienced significantly higher levels of depression than males, our results are consistent with literature cited on gender differences and depression $[2,3]$. The tendency for females to experience higher levels of depression has, in the past, been explained by differences in sex roles (Baron \& Matsuyama 1988), differences between the genders in coping or differences between the genders in reaction to stressors [11].

The level of satisfaction with financial position and accommodation were important variables influencing student depression. Students with the higher levels of financial satisfaction had lowers scores on the DASS as compared to students not satisfied with their financial position our study is in line with Andrews \& Wilding, 2004 [12-16]. This outcome indicates the importance of financial burden in determining the wellbeing of students. Study proved that those students who were unhappy living in the boarding displayed comparatively higher levels of depression $[17,18]$. Dissatisfaction with a living arrangement is a significant stressor for the students.

\section{References}

1. Eaton WW (2001) The sociology of mental disorders ( $3^{\text {rd }}$ edn.). Praeger, New York, USA.

2. Adewuya OA, Ola BA, Aloba 00, Mapayi BM, Oginni 00 (2006) Depression amongst Nigerian university students: Prevalence and socio demographic correlates. Social Psychiatry Epidemiology 41(8): 674 678.

3. Connell J, Barkham M, Mellor Clark J (2007) CORE-OM menta health norms of students attending university counselling services benchmarked against an age-matched primary care sample, British Journal of Guidance and Counselling 35(1): 41-57

4. Herrero J, Meneses I (2006) Short web-based versions of the perceived stress (PSS) and Centre for Epidemiological Studies Depression (CESD)
Scales: compassion to pencil and paper responses among Internet users Computer simian Behavior 2: 830-846.

5. McLennan J (1992) 'University blues': Depression among tertiary students during an academic year, British Journal of Guidance \& Counselling 20(2): 186-192.

6. Chen X, Rubin KH, Li B (1995) Depressed moods in Chinese children: Relations with school performance and family environment, Journal of Consulting and Clinical Psychology 63(6): 938-947.

7. Cumming ME (1995) Security, emotionality, and parental depression: A commentary. Developmental Psychology 31(3): 425-427.

8. Crocker J, Kayne NT, Alloy LB (1985) Comparing the self with others in depressed and non-depressed college students: Reply to McCauley, Journal of Personality and Social Psychology 48(6): 1579-1583.

9. Asarnow JR, Carlson GA, Guthrie D (1987) Coping strategies, selfperception, hopelessness, and perceived family environment in depressed and suicidal children, Journal of Consulting and Clinical Psychology 55(3):361-366.

10. Gotlib IH, Hammen CL (1992) Psychological aspects of depression: Toward a cognitive-interpersonal integration. Wiley, New York, USA.

11. Kelly WE, Kelly KE, Brown FC, Kelly HB (1999) Gender differences in depression among college students: A multicultural perspective. College Student Journal 33(1): 72-76.

12. Coombs RH (1991) Marital status and personal well-being: A literature review, Family Relations 40(1): 97-102.

13. Demitri M (2018) Depression in Children and Adolescents. Psych Central.

14. Lewinsohn PM, Gotlib IH, Seeley JR (1997) Depression-related psychosocial variables: Are they specific to depression in adolescents? Journal of Abnormal Psychology 106(3): 365-375.

15. Lovibond AD, Lovibond PF (1995). Manual for the Depression Anxiety.

16. Nolen Hoeksema S (1991) Responses to depression and their effects on the duration of depressive episodes, Journal of Abnormal Psychology 100(4): 569-582.

17. Nolen Hoeksema S, Girgus JS (1994) The emergence of gender differences in depression during adolescence, Psychological Bulletin 115(3): 424-443

18. Roberts R, Golding J, Towell T, Weinreb I (1999) The effects of economic circumstances on British students' mental and physical health. Journal of American College Health 48(30): 103-109.
ISSN: 2574-1241

DOI: 10.26717/BJSTR.2019.17.003031

Abou Bakar Idrees Awan. Biomed J Sci \& Tech Res

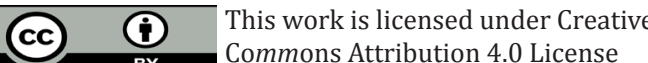

Submission Link: https://biomedres.us/submit-manuscript.php

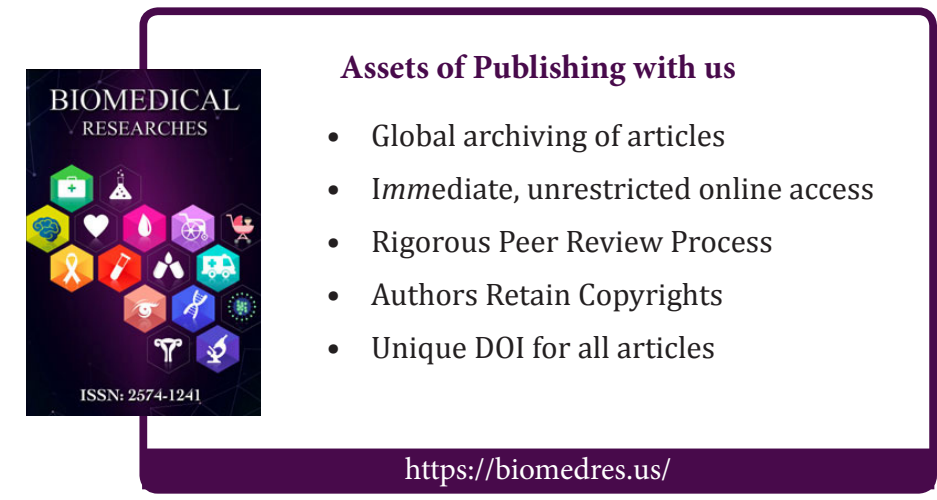

